"This article may not exactly replicate the final version published in the APA journal.

It is not the copy of record."

The published version may be found at http://www.apa.org/pubs/journals/xhp/

\title{
A magnocellular contribution to conscious perception via temporal object segmentation
}

\author{
Stephanie C. Goodhew, Hannah L. Boal and Mark Edwards \\ Research School of Psychology, The Australian National University
}

Word count: (main text): 7,269

Corresponding Author: Stephanie C. Goodhew

Address: Research School of Psychology (Building 39)

The Australian National University, Canberra, 0200

Email: stephanie.goodhew@anu.edu.au 


\begin{abstract}
The human visual system is continuously confronted with dynamic visual input. One challenge that the visual system must solve, therefore, is recognising when two distinct objects have appeared at a given location despite their brief presentation and rapid succession, that is, temporal object segmentation. Here we examined the role of magnocellular neurons in this process. We measured temporal object segmentation via object substitution masking (OSM), which reflects the failure to distinguish the target and mask as distinct objects through time. We isolated the selective role of magnocellular neurons by comparing performance under conditions of pulsed luminance pedestals, which are designed to saturate the magnocellular response, with that in a steady-pedestal condition which leaves both magnocellular and parvocellular channels available to process the target. Across two experiments, we found that OSM magnitude was enhanced under pulsed-pedestal conditions, in which the magnocellular response was impaired. This indicates that magnocellular neurons contribute to temporal object segmentation. Given that temporal object segmentation has consequences for which stimuli are consciously perceived, this demonstrates a functional mechanism via which magnocellular neurons contribute to determining the contents conscious perception. Implications for models of specialisation of dorsal and ventral cortical streams are discussed.
\end{abstract}


Keywords: magnocellular; dorsal stream; luminance pedestal; temporal object segmentation; visual masking; conscious perception; simultanagnosia.

The human visual system is continuously confronted with dynamic visual input. This means that the system must parse this ongoing input into discrete objects in order to transform it into the coherent and stable visual scene that we consciously perceive. For example, when walking down a crowded street, there are a large number of people, who are moving, and can disappear temporarily behind other objects. From this, the system needs to infer what stimulation belongs to a continuing object over time (e.g., the same person, despite changes in their appearance due to viewpoint variation and location), versus what belongs to distinct objects (e.g., two different people who might occupy the same location between successive glances). The visual system therefore regularly has to draw an inference of whether input from a given location belongs to a continuous object identity through time ("sustained object representation"), or two (or more) separate objects (“object segmentation”). Such inferences occur prior to conscious perception, but ultimately determine our subjective experience of the world. In this paper, we investigate the relative contribution of the two major classes of visual cells in object segmentation.

There are two major cell types that selectively process different aspects of visual stimuli: magnocellular $(\mathrm{M})$ cells and parvocellular $(\mathrm{P})$ cells. Compared with $\mathrm{P}$ cells, $M$ cells have faster conduction speeds, greater temporal sensitivity, that is, sensitivity to rapid changes in luminance over time (onsets, offsets, motion), greater sensitivity to luminance contrast, and process lower spatial frequencies (which generally corresponds to the 'gist' of a scene or stimulus), resulting in lower spatial acuity (Derrington \& Lennie, 1984; Legge, 1978; Livingstone \& Hubel, 1988). 
$\mathrm{M}$ and $\mathrm{P}$ cells are aligned in channels, which connect the retina to the striate cortex via the lateral geniculate nucleus (LGN), and which then connect predominately to the dorsal and ventral cortical processing streams (Livingstone \& Hubel, 1988; Schiller \& Logothetis, 1990). That is, although both M and P cells are present in both cortical streams (Maunsell, Nealey, \& DePriest, 1990; Merigan \& Maunsell, 1993; Nassi \& Callaway, 2007), M cells represent the major input into the dorsal cortical stream, and $\mathrm{P}$ cells the major input into the ventral stream. The dorsal stream projections reach posterior parietal regions including the motor cortex, whereas the ventral stream projects into the inferotemporal cortex in the temporal lobe, where object-responsive regions lie (Gautheir, Tarr, Anderson, Skudlarski, \& Gore, 1999; Grill-Spector, Kourtzi, \& Kanwisher, 2001; Grill-Spector, Tammar, Hendler, \& Malach, 2000; Kanwisher \& Yovel, 2006). It has been proposed that the P-ventral stream underlies conscious perception and identification of objects and the M-dorsal stream subserves unconscious visually-guided action, such that that the processing in this stream is impervious and inaccessible to conscious awareness (Goodale, 2008; Goodale \& Milner, 1992).

In support of the dissociation of function between the two streams, Goodale and Milner (1992) pointed to the neuropsychological case study DF, who suffered damage to ventral stream regions. This damage led to DF's inability to explicitly recognise an object or its properties (size, shape, or orientation, i.e., object agnosia), yet she was nonetheless able to accurately adjust the width between her finger and thumb to the appropriate size to grip the object. That is, DF demonstrated accurate motor behaviour to interact with an object that she apparently did not consciously perceive (Goodale, Milner, Jakobson, \& Carey, 1991; James, Culham, Humphreys, Milner, \& Goodale, 2003). Similar such dissociations between the perception of 
objects (e.g., distorted by visual illusions) on the one hand and unimpaired motor action on the other have also been reported with intact visual systems (e.g., Binsted, Brownwell, Vorontsova, Heath, \& Saucier, 2007; Haffenden, Schiff, \& Goodale, 2001). In contrast, patients with optic ataxia resulting from damage to dorsal regions can explicitly recognise objects, but are impaired in visually-guided interactions with objects (e.g., reaching, grasping) (Jakobson, Archibald, Carey, \& Goodale, 1991). Altogether, this evidence suggests that the ventral stream is implicated in the conscious perception of objects, and the dorsal stream in visually-guided action, which can be dissociated from conscious perception.

Clearly, therefore, there is evidence for specialisation of function between the dorsal and ventral streams. Additional evidence, however, does not support a rigid demarcation whereby perception is the exclusive domain of the ventral stream, and that functions subserved by the dorsal stream must necessarily be unconscious as suggested by Goodale and colleagues (Goodale, 2008; Goodale \& Milner, 1992; Goodale \& Westwood, 2004). For example, patient LM sustained damage to area $\mathrm{V} 5 / \mathrm{MT}+$, leading to impaired motion perception (akinetopisa or "motion blindness") (Zihl, Von Cramon, \& Mai, 1983). Area V5/MT+ is a component of the dorsal stream (Born \& Bradley, 2005), and yet it is LM's conscious perception of a property of objects (i.e., their motion) that is impaired. A similar such motion perception deficit can also be transiently induced in otherwise healthy systems via transcranial magnetic stimulation (TMS) applied to V5/MT+ (Beckers \& Zeki, 1995). This suggests that the dorsal stream also plays a role in conscious perception.

Although these motion studies implicate the dorsal stream in the conscious perception of object motion, it might be argued that this is distinct from conscious perception of object identity. Further evidence, however, also implicates $\mathrm{M}$ cells and 
the dorsal stream in conscious perception of object identity for static objects. Some such evidence arises from the literature on visual masking. Metacontrast masking, a commonly-used form of visual masking in which a snugly-surrounding but nonoverlapping mask (e.g., an annulus) impairs perception of a target (e.g., a disc), is thought to be the result of M-on-P inhibition. Metacontrast masking is strongest when the mask follows the target in time by about $50-100 \mathrm{~ms}$ (intermediate stimulus onset asynchrony; SOA). This is because at this SOA the onset of the mask produces a transient $\mathrm{M}$ channel response, which inhibits the slower $\mathrm{P}$ channel response conveying information about the target. Masking is reduced if the target-mask SOA is shorter, because then the rapid mask-induced $\mathrm{M}$ channel response occurs prior to the slower target $\mathrm{P}$ channel response, and masking is also weaker when SOA is longer, because this allows time for the $\mathrm{P}$ channel response to complete and a conscious percept of the target formed prior to the inhibition induced by mask onset (Breitmeyer \& Ganz, 1976; Breitmeyer \& Ögmen, 2006).

In addition to the temporal properties of metacontrast masking matching those expected from $\mathrm{M}$ and $\mathrm{P}$ interactions, further evidence in favour of this $\mathrm{M}$-on-P inhibition account of metacontrast masking is that masking is attenuated by red diffuse light (Breitmeyer \& Williams, 1990), or the use of a red mask (Pammer \& Lovegrove, 2001). Red light has been established to inhibit M cells, due to the presence of a subset (Type IV) of on-centre off-surround M cells whose surround is inhibited by red light in the receptive field (de Monasterio, 1978; Dreher, Fukada, \& Rodieck, 1976; Wiesel \& Hubel, 1966). The phenomenon of metacontrast masking and it being the consequence of M-on-P inhibition demonstrates that $\mathrm{M}$ cells can influence the conscious perception of objects. That is, it is the mask-induced M cell response that determines whether $\mathrm{P}$ cell representation of the target is consciously 
perceived. Although on the surface this might appear to reflect a detrimental effect of $\mathrm{M}$ cells on conscious perception, this is the product of the particular timing of the metacontrast masking paradigm. Under normal viewing conditions, $\mathrm{M}$ channel and $\mathrm{P}$ channel responses are initiated simultaneously in response to an object that is ultimately consciously perceived, without interference from a mask. In fact, the M channel may actually be essential in consolidating and rendering consciouslyaccessible the representation in the P channel (Bachmann, 1984). Consistent with this, more recent work has shown that the magnitude of priming effects derived from reaction times to identify targets (as left or right pointing arrows) that are preceded by a metacontrast-masked prime (either a left or right-pointing arrow) at different levels of prime contrast have been found to be best predicted by the known contrastsensitivity functions of M cells, rather than P cells (Tapia \& Breitmeyer, 2011). This suggests that contrary to the notion of $\mathrm{P}$ cells monopolising conscious perception of the target object, $\mathrm{M}$ cells also play an important role.

The evidence reviewed so far suggests that $\mathrm{M}$ cells influence the conscious perception of object identity for static objects, via either enhancing or suppressing a particular am object representation. This does not therefore imply that $\mathrm{M}$ cells represent this content. This makes sense from a functional perspective given the poorer spatial acuity of the $\mathrm{M}$ cells. However, there is some recent evidence that $\mathrm{M}$ cells might even contribute to determining which object representation is selected for representation in the first place. It is now widely accepted that feedback or re-entrant processing from anterior to poster visual regions is critically involved in rendering stimulus representations consciously accessible (Bullier, 2001; Di Lollo, 2010; Di Lollo, Enns, \& Rensink, 2000; Dux, Visser, Goodhew, \& Lipp, 2010; Lamme \& Roelfsema, 2000). Typically, however, the notion of feedback processing is focussed 
on re-entrant processes within the ventral stream that occur after the initial feedforward sweep initiated by a stimulus. But it has recently been shown that low spatial frequencies conveyed via an $\mathrm{M}$ channel input direct into frontal regions activate one or more candidate object template(s), representing preliminary guess(es) about object identity, and then feedback into temporal areas then to be integrated with the feedforward input, thereby facilitating explicit object recognition by constraining the number of candidate object representations (Bar, 2003; Bar et al., 2006; Kveraga, Boshyan, \& Bar, 2007). However, while this suggests that $\mathrm{M}$ cells can bias the system toward a particular object representation, it appears as though this is still mediated via interactions within the ventral stream.

Therefore, given the accumulating evidence that $M$ cells contribute to conscious perception of both moving and static objects, here we tested one possible instantiation for how this contribution could manifest. That is, while some previous work has implicated M cells in conscious perception (Tapia \& Breitmeyer, 2011) it did not offer a definitive mechanism via which this would happen. The exception to this is Bar's model of object recognition, however, this work focussed on recognition of isolated static object images. Yet one of the fundamental challenges of conscious object perception is parsing ongoing, dynamic visual input into discrete object representations. Here, therefore, we examined the role of $M$ cells in this challenge. We reasoned that temporal object segmentation, the crucial visual-cognitive process of recognising two distinct objects despite their close spatiotemporal proximity, would benefit from the greater temporal resolution of $\mathrm{M}$ cells. While P cells represent the finer details of objects, their temporal resolution is poor (Derrington \& Lennie, 1984; Legge, 1978; Livingstone \& Hubel, 1988). It makes sense, therefore, for M channel input to parse discrete objects through time from ongoing input. For example, 
if two, similar-looking objects occupy the same location at two points in time, then the visual system should be more likely to recognise this with enhanced $\mathrm{M}$ channel input (all other things being equal), whereas without this, the system should be more inclined to treat them as a single object, continuing and varying slightly in appearance over time.

In order to gauge this process of temporal object segmentation, we used object substitution masking (OSM), in which perception of a briefly-presented target object is impaired by a common-onsetting, temporally-trailing mask that neither overlaps nor shares common contours with the target (Di Lollo, et al., 2000; Goodhew, Visser, Lipp, \& Dux, 2011; for a review see Goodhew, Pratt, Dux, \& Ferber, 2013). Masking magnitude is quantified by subtracting target identification accuracy for trials where the mask temporally-trails after target offset (delayed mask offset condition), from control condition trials in which the target and mask offset simultaneously (simultaneous mask offset condition). OSM was chosen because extensive evidence implicates a failure of temporal object segmentation as the cause of the masking. That is, masking occurs when the target and four-dots from the target array and the trailing mask are mistaken for a single object continuing through time, resulting in the representation of the object for that location being updated to reflect the longer trailing mask, at the expense of the target (Goodhew, Gozli, Ferber, \& Pratt, 2013; Goodhew, Pratt, et al., 2013; Guest, Gellatly, \& Pilling, 2012; Hirose et al., 2007; Lim \& Chua, 2008; Lleras \& Moore, 2003; Luiga \& Bachmann, 2008; Moore \& Lleras, 2005; Pilling \& Gellatly, 2010). This means that OSM magnitude is inversely related to temporal object segmentation. That is, the greater the magnitude of masking, the greater the failure to segment (Goodhew, Pratt, et al., 2013). 
When the target and mask are presented in different colours or luminance polarities, OSM magnitude is reduced (Luiga \& Bachmann, 2008; Moore \& Lleras, 2005). This supports the notion that OSM reflects overzealous temporal fusion of the target and mask, as different colours or luminance polarities are spatial object segmentation cues (Badcock, Clifford, \& Khuu, 2005; Edwards, 2009; Wenderoth, 1996). Similarly, the extent to which a trailing mask impairs target perception is dependent on whether its spatiotemporal properties are conducive to perceiving it as the same object as the four-dots that were presented during the target array, and thereby susceptible to object updating (Lleras \& Moore, 2003). Finally, preview of the mask prior to the onset of the target array attenuates masking, even though the preview is not predictive of subsequent target location (e.g., four-dot masks previewed at both target and all distractor locations). This preview advantage is thought to be mediated by encouraging the visual system to treat the mask as an object in its own right, preventing the target from being integrated with it (Neill, Hutchison, \& Graves, 2002). Altogether, then, OSM reflects object-updating, or the failure to segment the target plus four dots of the target from the trailing four-dot mask.

In order to examine the contribution of $M$ cells to temporal object segmentation, we employed a pulsed versus steady pedestal paradigm, which relies on the differential contrast sensitivities of $\mathrm{M}$ and $\mathrm{P}$ cells. In both conditions, a pedestal (a spatially-homogenous background) is presented at each stimulus location (e.g., four locations around central fixation). The pedestals have a higher luminance than the background, and thus their onset represents a rapid increase in luminance at the stimulus locations. The key difference between the pulsed and steady pedestal conditions is the timing of this luminance increase. Given that the $\mathrm{M}$ cells are more 
sensitive to rapid changes in luminance, when the pedestal onset occurs concurrently with the target and mask stimuli (pulsed-pedestal), it saturates any object-selective $\mathrm{M}$ cell response. Whereas when this increase occurs in advance (e.g. 1 second) of the target (steady-pedestal), the transient response of $\mathrm{M}$ cells induced by its onset has had time to diminish by the time of target-array onset, leaving both $\mathrm{M}$ and $\mathrm{P}$ channels available to process the target and subsequent trailing mask. Comparing target perception in these two conditions can therefore reveal the selective contribution of $\mathrm{M}$ cells to perception (Leonova, Pokorny, \& Smith, 2003; Pokorny, 2011; Yeshurun \& Sabo, 2012).

Given the temporal superiority of the $\mathrm{M}$ cells, and that the process of object segmentation across time requires greater temporal precision, we predicted $\mathrm{M}$ cells are implicated in this process. To test the role of $\mathrm{M}$ cells in temporal object segmentation, we combined OSM - a metric of temporal object segmentation - with a pedestal manipulation to selectively isolate the role of M cells. Specifically, we thought that when the visual system is confronted with two events close in time, (target + mask) and (mask only), the role of the $\mathrm{M}$ cells would be to encourage the system to treat these two events as reflecting distinct objects, thereby facilitating the conscious perception of them both. This means that when the contribution of the M cells is diminished by the pulsed pedestal, the visual system should be more likely to treat these two events as belonging to the same object. When this happens, since in OSM the trailing mask is presented second in the sequence, and for longer than the target, it will be consciously perceived at the expense of target, thereby increasing masking magnitude. Thus, if $\mathrm{M}$ cells are critically involved in temporal object segmentation, then the magnitude of masking should increase in the pulsed-pedestal condition compared to the steady-pedestal condition. 


\section{EXPERIMENT 1}

The purpose of Experiment 1 was to test the potential role of $\mathrm{M}$ cells in temporal object segmentation. To do this, we compared the magnitude of OSM under steady versus pulsed-pedestal conditions. If $\mathrm{M}$ cells underlie temporal object segmentation, then OSM magnitude should be greater in the pulsed relative to the steady-pedestal condition.

\section{Method}

\section{Participants}

Twenty participants (13 female) were tested individually and provided written informed consent prior to participation (Mean age $=20.95$ years, $\mathrm{SD}=2.33$ ). All reported normal or corrected-to-normal vision.

\section{Stimuli and apparatus}

Stimuli were presented on a cathode-ray tube (CRT) gamma-corrected monitor with a $75 \mathrm{~Hz}$ refresh rate. Viewing distance was fixed at $44 \mathrm{~cm}$ with a chinrest. Stimuli were programmed in Matlab using the Psychophysics Toolbox (Brainard, 1997). The background was dark-grey $\left(9.6 \mathrm{~cd} / \mathrm{m}^{2}\right)$. Four lighter grey $\left(56.7 \mathrm{~cd} / \mathrm{m}^{2}\right)$ pedestals $\left(1.7^{\circ} \times 1.7^{\circ}\right)$ arranged in a plus-sign configuration around a small white fixation cross in the centre of the screen (distance from fixation to pedestal $=8.4^{\circ}$ ). The target object was a black Landolt $\mathrm{C}\left(\right.$ diameter $=1.4^{\circ}$, thickness $=.3^{\circ}$, with four black squares $\left(.5^{\circ} \times .5^{\circ}\right)$ on the corners of an imaginary square centred on the $\mathrm{C}$. The gap in the $\mathrm{C}$ was either on the left or the right of the object ( size of gap $=.3^{\circ}$ ), and the target could appear in any of the four locations on a given trial, and distractors appeared in the other three locations. Distractors were also Landolt Cs. The target was differentiated from the distractors by the presence of the four-dot mask.

\section{Procedure}


Each trial consisted of the following sequence: A fixation-cross screen was displayed for $1000 \mathrm{~ms}$. This either did also contain the four pedestals (steady-pedestal condition), or did not (pulsed-pedestal condition). Then the target array was presented for $53 \mathrm{~ms}$ (note that the steady and pulsed pedestal conditions involved identical physical stimuli in the target array and from then on in the trial). On the delayed mask offset trials, the four-dot mask and pedestals were presented for a further $160 \mathrm{~ms}$, whereas on the simultaneous offset trials, blank pedestals were presented for a further 160ms. Next, in both conditions, blank pedestals were presented until a response was registered. Participants' task was to identify whether the gap in the target Landolt C was on the left or right of the object (unspeeded). Response keys were the left and right arrow keys on a standard keyboard. The inter-trial interval (during which the screen was blank) was 1000ms (see Figure 1).

The orientation of the gap in the target, its location around fixation, and mask duration (0 [simultaneous offset] or $160 \mathrm{~ms}$ [delayed mask offset] trailing mask durations) were randomly assigned for each trial with the constraint that there were an equal number of trials per target identity, location, and mask duration within each block. Pedestal condition was blocked within participants. Participants completed 128 trials per pedestal condition and rest breaks were provided halfway through and at the end of each pedestal block, the length of which was at the discretion of the participant.

\section{Results \& Discussion}

The first five trials from each pedestal block were used as practice and thus were removed from the analysis. Data from two participants were excluded from the analysis because their accuracy was too poor to observe meaningful variation across conditions that was not an artefact of floor effects (overall average accuracy $<=60 \%$ 
where chance is $50 \%$ ). Average overall accuracy for the remaining 18 datasets was $71.25 \%$.

One participant was also excluded due to showing strong reverse masking effects in both conditions (average accuracy was $16 \%$ and $8 \%$ higher in the delayed than simultaneous offset conditions in the steady and pulsed pedestal conditions respectively). Although the mask duration by luminance pedestal interaction was significant if this data were included $\left(p=.028, \eta_{\mathrm{p}}{ }^{2}=.253\right)$, given that we were interested in how OSM is affected by luminance pedestals, the absence of a masking effect meant that their data were uninformative.

The remaining 17 datasets were submitted to a 2 (pedestal condition) x 2 (mask duration) repeated measures ANOVA (see Figure 2). This revealed a significant main effect of mask duration, $F(1,16)=14.33, p=.002, \eta_{\mathrm{p}}{ }^{2}=.472$, such that target identification accuracy was higher on simultaneous mask offset trials $(\mathrm{M}=74.32 \%)$ than on delayed mask offset trials $(\mathrm{M}=68.69 \%)$. The main effect of pedestal did not reach significance, $F(1,16)=3.13, p=.096, \eta_{\mathrm{p}}{ }^{2}=.163$. The interaction between mask duration and pedestal on target identification accuracy was significant, $F(1,16)=4.68$, $p=.046, \eta_{\mathrm{p}}{ }^{2}=.226$. This interaction reflects that masking magnitude (simultaneous delayed mask offset accuracy) was greater in the pulsed pedestal condition $(\mathrm{M}=$ $7.61 \%)$ than in the steady pedestal condition $(\mathrm{M}=3.64 \%)$. Planned comparisons revealed that this masking magnitude was significant in the pulsed pedestal condition, $t(16)=4.45, p<.001, d=.95^{1}$, but not in the steady pedestal condition, $t(16)=2.81$, $p=.053, d=.47$.

It is noteworthy that the magnitude of the masking in the steady-pedestal condition here was small $(3.64 \%)$ and not quite significant $(p=.053)$. There are two major possible reasons for this. Firstly, it could be that the experiment was simply 
under-powered. Secondly, it could be that in the steady-pedestal condition, the pedestals visible during the fixation screen could have served as an object segmentation cue. It has been established that prior exposure to the four-dot mask, even when not predictive of subsequent target location, reduces masking (Lim \& Chua, 2008; Neill, et al., 2002), as does prior presentation of 'placeholder' stimuli at subsequent target and distractor locations, even though this is not informative of target identity (e.g., rings at stimulus locations, which later have parts offset to reveal a Landolt C) (Gellatly, Pilling, Carter, \& Guest, 2010; Guest, et al., 2012). It is possible, therefore, that the pedestals in the sustained-pedestal condition served to encourage the system to treat the stimuli at that location as different to the subsequent trailing mask, thus reducing masking. Such an effect would not have been observed in the pulsed-pedestal condition, because here there was no preview of the pedestal prior to the onset of the target array. These possibilities were tested in Experiment 2, where we designed a steady versus pulsed pedestal paradigm where placeholders were present in both conditions, increased the number of trials in each condition, and a practice block was introduced.

\section{EXPERIMENT 2}

The main purpose of Experiment 2 was to test whether the interaction between pedestal condition and mask duration obtained in Experiment 1, such that masking magnitude was greater with the pulsed pedestal, could be replicated under conditions that eliminated any potential placeholder difference between the two pedestal conditions. To do this, now both the pulsed and steady pedestal conditions included placeholders during the fixation display. In order to still permit a rapid increase in luminance of the pedestal in the pulsed-pedestal condition, the pedestals displayed during the one-second fixation display in this condition were grey, and then changed 
to white simultaneous with the onset of the target array. In the steady-pedestal condition, in contrast, the pedestals were white throughout the fixation as well as the target array displays (thus no change in luminance). We also increased the sensitivity of Experiment 2 by including practice prior to the experiment and doubled the number of trials per condition that each observer contributed. If $\mathrm{M}$ cells underlie temporal object segmentation, then masking magnitude should be greater under pulsed compared to steady pedestal conditions.

\section{Method}

\section{Participants}

Twenty-two participants (21 female) were tested individually and provided written informed consent prior to participation (Mean age $=20.95$ years, $\mathrm{SD}=2.44$ ). All reported normal or corrected-to-normal vision.

\section{Stimuli and apparatus}

Stimuli and apparatus were identical to Experiment 1 with the following exceptions. In the pulsed-pedestal condition, pedestals were grey $\left(56.7 \mathrm{~cd} / \mathrm{m}^{2}\right)$ during the fixation display, and changed to white $\left(108.5 \mathrm{~cd} / \mathrm{m}^{2}\right)$ in the target array. In the steady-pedestal condition, pedestals were white throughout the trial. Crucially, therefore, from the onset of the target array onwards, the two pedestal conditions were identical. Once again, it was only the presentation during the fixation display and thus the change in luminance concurrent with the onset of the target array that differed between the two pedestal conditions.

\section{Procedure}

The procedure for Experiment 2 was identical to Experiment 1 with the following exceptions. On each trial, a fixation-cross screen was still displayed for $1000 \mathrm{~ms}$, however now this invariably contained four pedestals, which were either white 
(steady-pedestal condition), or grey (pulsed-pedestal condition) (see Figure 3). Also, prior to commencing an experimental block, participants completed a practice block, whereby target exposure duration began very slowly and progressively sped up every two trials until 12 trials were completed during which participants were given feedback on the screen on each trial as to whether their response was correct or incorrect. If a participant scored less than $75 \%$ correct on the practice block, then they completed it again (until they reached an average of at least $75 \%$ correct). For the experiment proper, participants completed 256 trials per pedestal condition, and again rest breaks were provided halfway through and at the end of each pedestal block, the length of which was at the discretion of the participant.

\section{Results \& Discussion}

Data from one participant was excluded from the analysis because they only completed half as many trials as the other participants, and one participant was also excluded due to showing strong reverse masking effects in both conditions (average accuracy was $14 \%$ and $2 \%$ higher in the delayed than simultaneous offset conditions in the steady and pulsed pedestal conditions respectively). Although the mask duration by luminance pedestal interaction was actually stronger if this participant's data were included $\left(p=.014, \eta_{\mathrm{p}}{ }^{2}=.268\right)$, given that we were interested in how OSM is affected by luminance pedestals, the absence of a masking effect meant that their data were uninformative.

The remaining 20 datasets were submitted to a 2 (pedestal condition) x 2 (mask duration) repeated measures ANOVA (see Figure 4). This revealed a significant main effect of mask duration, $F(1,19)=25.47, p<.001, \eta_{\mathrm{p}}{ }^{2}=.573$, such that target identification accuracy was higher on simultaneous mask offset trials $(\mathrm{M}=69.98 \%)$ than on delayed mask offset trials $(\mathrm{M}=65.98 \%)$. The main effect of pedestal 
condition was not significant $(F<1)$. The interaction between mask duration and pedestal on target identification accuracy was significant, $F(1,19)=5.74, p=.027, \eta_{\mathrm{p}}{ }^{2}$ $=.232$. This interaction is driven by the fact that masking magnitude (simultaneous delayed mask offset accuracy) was larger in the pulsed pedestal condition $(\mathrm{M}=$ $5.43 \%)$ than in the steady pedestal condition $(\mathrm{M}=2.58 \%)$. Planned comparisons revealed that this masking magnitude was significant in the pulsed pedestal condition, $t(19)=4.97, p<.001, d=.59$ and also in the steady pedestal condition, $t(19)=2.93, p$ $=.009, d=.39$ (see Figure 5). There was no significant difference in accuracy between the pedestal conditions at either the simultaneous, $t(19)=1.27, p=.220, d=$ .30 , or delayed mask offset conditions, $t(19)=.51, p=.619, d=.10$, revealing that it was selectively masking magnitude that was affected, rather than accuracy differentially at either particular mask duration.

Crucially, the present results demonstrate that even when both pedestal conditions have placeholders visible during the fixation display, masking is still stronger when the selective contribution of $M$ cells is impaired via the pulsed pedestal. This indicates that the interaction obtained in Experiment 1 is not an artefact of the steady-pedestal condition providing placeholders that signalled the location of stimuli in the upcoming target array. Instead, it reflects the fact that masking magnitude is increased when the contribution of $\mathrm{M}$ cells is attenuated. This suggests that $\mathrm{M}$ cells are involved in temporal object segmentation. Moreover, significant masking was now present in both conditions, also revealing that the interaction does not necessarily reflect the presence of masking in the pulsed versus its absence in the steady-pedestal condition, but can be a product of differences in masking magnitude that are each significant in their own right.

\section{General Discussion}


Here we tested the role of $M$ cells in temporal object segmentation, that is, the conscious perception of two distinct objects at a given location in rapid succession. To do this, we examined OSM magnitude, which reflects a failure of temporal segmentation (e.g., Goodhew, Pratt, et al., 2013), under conditions pulsed-pedestals, which selectively saturate the M cells with that under steady pedestals which leaves both the $\mathrm{M}$ and $\mathrm{P}$ responses intact (Leonova, et al., 2003; Pokorny, 2011; Yeshurun \& Sabo, 2012). Both Experiment 1 and Experiment 2 revealed an interaction between the type of pedestal (steady versus pulsed), and mask duration. This interaction reflected the fact that masking magnitude was enhanced when a pulsed-pedestal compared to when a steady-pedestal was used. Given that a pulsed-pedestal saturates $M$ cells with luminance at the same time that the target and mask appear, thereby impairing any object-selective response, this implicates $M$ cells in facilitating the visual system recognising the target and mask in OSM as distinct objects despite their close spatiotemporal proximity. That is, $\mathrm{M}$ cells facilitate temporal object segmentation. Given that the non-conscious inference that the target and mask reflect a single object in OSM results in a failure to consciously perceive the target, this implicates $\mathrm{M}$ cells in conscious object perception.

It is important to note that there was no evidence for an $M$ channel (or dorsal stream) representation of the target object in our experiments. This is because there was no main effect of pedestal-type on target identification accuracy. That is, participants were on average no better at identifying the target with a steady than with a pulsed pedestal. Instead, the pulsed pedestal selectively affected the magnitude of masking (and therefore temporal object segmentation). Given the broadbrand spatial frequency profile of our target object Landolt Cs, it makes sense that representation of the target object would instead be subserved by $\mathrm{P}$ cells and the ventral stream. The 
role of M cells was to help the system to help 'pull apart' or differentiate two object representations vying access to consciousness and thereby represent them both, rather than merely representing one at the expense of the other. Our results, therefore, are consistent with previous suggestions that $\mathrm{M}$ cells are indeed influencing the contents of conscious perception of static objects (e.g., Tapia \& Breitmeyer, 2011). Our results, however, extend on notion of merely being 'involved', to suggest that they are implicated in temporal object segmentation - a fundamental visual-cognitive process in our construction of the world around us from dynamic input.

\section{Relationships between temporal object segmentation measured via OSM and dorsal simultanagnosia}

$\mathrm{M}$ cells represent the major input into the dorsal cortical stream, and $\mathrm{P}$ cells the major input into the ventral stream (Derrington \& Lennie, 1984; Legge, 1978). Given the role of $\mathrm{M}$ cells in conscious object perception, it might therefore be expected that the dorsal cortical stream has an influence too. Interestingly, simultanagosnia resulting from dorsal-stream damage is a neuropsychological condition characterised by markedly slowed visual processing producing an inability to consciously perceive more than one object at a given point in time (e.g., Duncan et al., 2003; Luria, 1959). Dorsal simultanagnosia, therefore, could be conceptualised as an extreme version of a failure to segment objects close in space and time, which we can simulate in healthy individuals via OSM. This suggests that the dorsal cortical stream, in addition to $\mathrm{M}$ cells, may also contribute to temporal object segmentation.

\section{Implications for models of specialisation of cortical function}

The findings that $\mathrm{M}$ cells underlie temporal object segmentation suggests that the absolute dichotomy whereby $\mathrm{P}$ cells and the ventral cortical stream have an exclusive monopoly on conscious object perception (e.g., Goodale, 2008; Goodale \& 
Milner, 1992) is untenable. Instead, while there is clearly functional specialisation, conscious object perception recruits the spatial acuity of $\mathrm{P}$ cells to represent objects and the temporal resolution of $\mathrm{M}$ cells to resolve object representations across time. This is consistent with recent suggestions that the perception versus action dissociation and its mapping onto the ventral and dorsal streams has been over-stated (Hesse, Ball, \& Schenk, 2012; McIntosh \& Schenk, 2009). Historically, prior to Goodale and Milner (1992), it had been suggested that the ventral stream is the "what" pathway and the dorsal stream the "where" pathway (Mishkin \& Ungerleider, 1982; Mishkin, Ungerleider, \& Macko, 1983). That is, the ventral and dorsal streams subserved stimulus identification and spatial localisation respectively. Our results are more consistent with this conceptualisation, if the where in space is extended to incorporate where in time an object begins and ends.

\section{The competing demands of segmentation and integration in everyday vision}

Temporal object segmentation is a crucially important visual-cognitive process. However, it reflects just one possible outcome of an inference the visual system needs to frequently and rapidly draw. If the visual system indiscriminately segmented all available input, then we would be unable to perceive an object that continues across time and space. For example, when walking down a crowded street, it is possible that a new person occupies previously-attended location replacing another person, but sometimes the same object continues at that location, or even appears in a new location. If the visual system invariably segmented, then we would be unable to recognise such a continuing object. OSM is designed such that the correct response to identify the target requires segmentation of the target from the trailing mask. But rather than a 'failure' of vision, masking reflects the visual system reaching a particular non-conscious inference given the stimulus conditions it is 
confronted with. That is, it reflects the operation of the same functional mechanism that allows us to perceive a continuing object identity across time and space.

Here we have found that $M$ cells are conducive to temporal object segmentation. Given that $\mathrm{P}$ cells have a more sustained response, it seems plausible that they would facilitate a sustained object representation, for example, keeping track of an object identity across occlusion or interruption (e.g., Burke, 1952; Hein \& Moore, 2012; Hollingworth \& Franconeri, 2009; Pylyshyn \& Storm, 1988; Richard, Luck, \& Hollingworth, 2008). It remains to be comprehensively established whether the system has default biases toward segmentation versus sustaining representations under particular conditions, for example, task demands or recent visual experience, and the time-course of such biases. Recent evidence suggests that perihand or nearhand space (the visual field around an observer's hands) is the purview of upregulated $\mathrm{M}$ cell input, which facilitates temporal object segmentation inferences (Brockmole, Davoli, Abrams, \& Witt, 2013; Goodhew, Gozli, et al., 2013; Gozli, West, \& Pratt, 2012; a pattern first identified by Previc, 1990). This suggests that there are at least some circumstances where a default bias to segment exists, but it remains to be seen how flexibly the system can switch between such states, and the repertoire of factors that elicit such states. For example, whether it is limited to stimulus factors (such as luminance pedestals) and the proximity of observer's hands, or whether more cognitive factors such as task demands and recent visual experience also have an effect.

\section{Implications for OSM as a form of visual masking}

One aspect of the present results that is worth discussing is what might be considered the modest magnitude of the masking effects, particularly in Experiment 2. We see three possible explanations for this. First, it is possible that this arose from the 
use of the pedestals, which necessarily mark the location of the upcoming stimuli in the target array. Although the pedestals appeared in all four possible stimulus locations, and therefore never served as a spatial cue to differentiate the location of the target from distractors, they did provide a visual marker that delineates the subset of locations within the visual field in which stimuli (targets + distractors) will appear. While prior OSM studies have most commonly used fixed stimulus locations, these were not demarcated with visual a signal, as was necessary here with the pedestal design. This may have allowed the 'spotlight' of attention to be precisely focussed at a particular location (Eriksen \& Hoffman, 1972; Posner \& Cohen, 1984), increasing the likelihood of the target location being attended, or perhaps participants were able to split their attention amongst the four non-contiguous locations (multiple spotlights; M. Muller, Malinowski, Gruber, \& Hillyard, 2003). Alternatively, the pedestals may have permitted observers to adopt a diffuse attentional set such that resources were applied uniformly to all of the stimulus locations as well as the space in between them (distributed zoom lens; Eriksen \& St. James, 1986; Eriksen \& Yeh, 1985; N. G. Muller, Bartelt, Donner, Villringer, \& Brandt, 2003). Any of these attentional effects could have led to an attenuated masking magnitude (see Neill, et al., 2002). We are currently investigating the relationship between different attentional modes or styles, and their implications for temporal object segmentation as measured by OSM.

Second, the decrease in masking magnitude from Experiments 1 to 2 could reflect the fact that in Experiment 1, the contrast between the target and the background was lower (black on grey) than Experiment 2 (black on white). While previous research has found that masking magnitude is modulated by the similarity in luminance between the target and mask (Luiga \& Bachmann, 2008), there has been no systematic investigation of the similarity in luminance between the target and the 
background on which it appears. It could be that the object-updating mechanism that characterises OSM is influenced by the relationship between objects in the foreground and their background, such that masking is facilitated when the target is more similar to the background. Future research should explore systematically test this possibility, as it would provide important new insight into the factors that affect OSM and temporal object segmentation more broadly.

Third, Experiment 2 had twice as many trials as Experiment 1 and also included a practice block. If masking magnitude is susceptible to practice or training effects, then this would be interesting as it would tell us that the temporal object segmentation processes are susceptible to such cognitive context as recent experience. Future research could disentangle these possible explanations, as they each have the potential to advance our theoretical understanding of OSM as the visual-cognitive mechanisms it reflects. For the present purposes, however, the masking magnitudes obtained were sufficiently large and statistically reliable to demonstrate that masking magnitude is increased when the M-cell contribution is impaired by a pulsed pedestal, indicating that M-cells subserve temporal object segmentation.

Finally, our results also suggestive of important implications for OSM itself and the functional mechanisms it taps in relation to other forms of visual masking. It is striking that the effect of $\mathrm{M}$ cells here on OSM is qualitatively different to effects in metacontrast masking. That is, OSM is a relatively recent addition to the family of visual masking techniques (Enns \& Di Lollo, 2000), whose use spans centuries in experimental psychology (Alpern, 1952, 1953; Baxt, 1871, 1982; Werner, 1935). It has been debated, therefore, whether OSM is in fact a variant of the more traditional metacontrast masking, which also employs a mask that does not spatially overlap the target (Breitmeyer \& Ögmen, 2000; Francis \& Hermens, 2002). More recently, there 
has some evidence for at least degrees of dissociation (i.e., quantitative differences) between metacontrast masking and OSM. For example, the distribution of attention during target-array exposure is a necessary condition for OSM (Di Lollo, et al., 2000; Dux, et al., 2010; Goodhew, Pratt, et al., 2013; but see also Argyropoulos, Gellatly, Pilling, \& Carter, 2013), whereas metacontrast masking occurs with a fixed target location (Breitmeyer \& Ögmen, 2006), and instead its magnitude is merely modulated by attention (Boyer \& Ro, 2007; Ramachandran \& Cobb, 1995; Shelley-Tremblay \& Mack, 1999). Similarly, metacontrast masks applied to flankers in a crowding paradigm (e.g., Bouma, 1970; Pelli \& Tillman, 2008) will eliminate the detrimental effect of flankers of target perception, whereas OSM masks applied to these same flankers will not (Chakravarthi \& Cavanagh, 2009). However, these could be interpreted as OSM simply reflecting a weaker version of metacontrast masking, especially given the more sparse contours of the four-dot mask compared to, for example, an annulus mask in metacontrast masking. Here, however, we found that saturating $\mathrm{M}$ cells with luminance increased OSM magnitude, whereas it has been shown that inhibiting $\mathrm{M}$ cells with red diffuse light reduces metacontrast masking (Breitmeyer \& Williams, 1990). That is, this is the first evidence that the same functional manipulation (selectively impairing the response of $\mathrm{M}$ cells) produces qualitatively different results in OSM and metacontrast masking. This would appear to suggest that they are indeed distinct forms of visual masking with different underlying mechanisms. However, further research should directly compare metacontrast masking and OSM with a single manipulation targeted to affect $\mathrm{M}$ cells to establish this more definitively.

\section{Avenues for future research into M-cell contributions to conscious perception}


It could be suggested that the pulsed pedestal manipulation in the present experiment was interfering with the receptor level response. This is unlikely for several reasons. Pokorny's work (Leonova, et al., 2003; Pokorny, 2011) provides compelling evidence that the pulsed pedestal selectively affects M-cells, and the pedestal paradigm has been used to infer $\mathrm{M}$ and $\mathrm{P}$ contributions to other cognitive processes (such as exogenous attention favouring $\mathrm{P}$ cell processing at the attended location; Yeshurun \& Sabo, 2012). Second, if the pulsed pedestal were interfering with responses at the receptor level in the present experiments, then this would be evident in overall effects on target perception, that is, lower target identification accuracy under pulsed pedestal conditions. But in neither experiment did we observe an overall effect of the pulsed pedestal on target identification. Instead, it selectively affected masking magnitude, implicating $\mathrm{M}$ cells in temporal object segmentation and therefore conscious object perception. However, future research could rule out the possibility of receptor-level contributions definitively by replicating the present results with dichoptic or interocular stimulus presentations.

Although the present result is clear evidence that $\mathrm{M}$ cells contribute to temporal object segmentation, of course, having evidence from a variety of methods provides the strongest evidence for a particular conclusion. Converging evidence for the role of $\mathrm{M}$ cells in temporal object segmentation could be obtained from a number of methods. For example, as mentioned previously, red diffuse light attenuates $\mathrm{M}$ cell responses (de Monasterio, 1978; Dreher, et al., 1976; Wiesel \& Hubel, 1966), and therefore OSM magnitude should be increased when stimuli are presented on a red background compared to when they are presented on a luminance-matched green background. Similarly, adapting to high temporal frequency flicker, which temporarily diminishes the functioning of $\mathrm{M}$ cells, should increase masking. Finally, 
there is growing evidence that the presentation of an image of a human face displaying a fearful expression induces a transient bias to M-cell over P-cell processing (Bocanegra \& Zeelenberg, 2009, 2011). In this case, masking magnitude should be reduced after the presentation of a fearful face image. These manipulations could provide converging evidence for the role of $\mathrm{M}$ cells in temporal object segmentation.

\section{Conclusion}

To summarise, $\mathrm{M}$ cells contribute to temporal object segmentation, that is, our ability to consciously perceive two distinct stimuli, despite their close spatiotemporal proximity. Temporal object segmentation has consequences for conscious visual perception, in that a failure to segment results in the loss of conscious perception of an object. This, therefore, implicates $\mathrm{M}$ cells and possibly the dorsal cortical stream in conscious object perception. 


\section{Notes}

1. We calculated Cohen's $d$ using the online calculator provided by Becker (2000) for correlated samples calculated from means and standard deviations. 


\section{Acknowledgements}

S.C.G is the recipient of an Australian Research Council (ARC) Discovery Early Career Research Award (DE140101734) and M.E. an ARC Discovery Grant (DP110104553). Correspondence regarding this study should be addressed to

Stephanie Goodhew (stephanie.goodhew@anu.edu.au), Research School of Psychology, The Australian National University. The authors would like to thank Peter Zhang for assistance with the data collection. 


\section{References}

Alpern, M. (1952). Metacontrast: Historical introduction. American Journal of Optometry, 29, 631-646.

Alpern, M. (1953). Metacontrast. Journal of the Optical Society of America, 43, 648657. doi: 10.1364/JOSA.43.000648

Argyropoulos, I., Gellatly, A., Pilling, M., \& Carter, W. (2013). Set size and mask duration do not interact in object-substitution masking. Journal of Experimental Psychology: Human Perception and Performance, 39(3), 646661. doi: $10.1037 / \mathrm{a} 0030240$

Bachmann, T. (1984). The process of perceptual retouch: Nonspecific afferent activation dynamics in explaining visual masking. Perception \& Psychophysics, 35(1), 69-84. doi: 10.3758/BF03205926

Badcock, D. R., Clifford, C. W. G., \& Khuu, S. K. (2005). Interactions between luminance and contrast signals in global form detection. Vision Research, 45(7), 881-889. doi: 10.1016/j.visres.2004.09.042

Bar, M. (2003). A cortical mechanism for triggering top-down facilitation in object recognition. Journal of Cognitive Neuroscience, 15(4), 600-609. doi: $10.1162 / 089892903321662976$

Bar, M., Kassam, K. S., Ghuman, A. S., Boshyan, J., Schmidt, A. M., Dale, A. M., . . Halgren, E. (2006). Top-down facilitation of visual recognition. Proceedings of the National Academy of Sciences, 103(2), 449-454. doi: 10.1073/pnas.0507062103

Baxt, N. (1871). Über die Zeit, welche nötig ist, damit ein Gesichtseindruck zum Bewusstsein kommt und über die Grösse (Extension) der bewussten 
Wahrnehmung bei einem Gesichtseindrucke von gegebener Dauer Pfluegers Arch Gesamte Physiol Menschen Tiere, 4, 325-336.

Baxt, N. (1982). On the time necessary for a visual impression to come into consciousness. Psychological Research, 44(1), 1-12. doi:

10.1007/BF00308551

Becker, L. A. (2000). Effect size calculators, from http://www.uccs.edu/ lbecker/

Beckers, G., \& Zeki, S. (1995). The consequences of inactivating areas V1 and V5 on visual motion perception. Brain, 118(1), 49-60. doi: 10.1093/brain/118.1.49

Binsted, G., Brownwell, K., Vorontsova, Z., Heath, M., \& Saucier, D. (2007).

Visuomotor system uses target features unavailable to conscious awareness. Proceedings of the National Academy of Sciences, 104(31), 12669-12672. doi: 10.1073/pnas.0702307104

Bocanegra, B. R., \& Zeelenberg, R. (2009). Emotion improves and impairs early vision. Psychological Science, 20(6), 707-713. doi: 10.1111/j.14679280.2009.02354.x

Bocanegra, B. R., \& Zeelenberg, R. (2011). Emotion-induced trade-offs in spatiotemporal vision. Journal of Experimental Psychology: General, 140(2), 272-282. doi: 10.1037/a0023188

Born, R. T., \& Bradley, D. C. (2005). Structure and function of visual area MT. Annual Review of Neuroscience, 28, 157-189. doi: 10.1146/annurev.neuro.26.041002.131052

Bouma, H. (1970). Interaction effects in parafoveal letter recognition. Nature, 226(5241), 177-178.

Boyer, J., \& Ro, T. (2007). Attention attenuates metacontrast masking. Cognition, 104(1), 135-149. 
Brainard, D. H. (1997). The psychophysics toolbox. Spatial Vision, 10(4), 433-436. doi: $10.1163 / 156856897 X 00357$

Breitmeyer, B. G., \& Ganz, L. (1976). Implications of sustained and transient channels for theories of visual pattern masking, saccadic suppression, and information processing. Psychological Review, 83(1), 1-36. doi: 10.1037/0033-295X.83.1.1

Breitmeyer, B. G., \& Ögmen, H. (2000). Recent models and findings in visual backward masking: A comparison, review, and update. Perception \& Psychophysics, 62(8), 1572-1595. doi: 10.3758/BF03212157

Breitmeyer, B. G., \& Ögmen, H. (2006). Visual masking: Time slices through conscious and unconscious vision (2nd ed.). New York, NY: Oxford University Press.

Breitmeyer, B. G., \& Williams, M. C. (1990). Effects of isoluminant-background color on metacontrast and stroboscopic motion: Interactions between sustained (P) and transient (M) channels. Vision Research, 30(7), 1069-1075. doi: $10.1016 / 0042-6989 \% 2890 \% 2990115-2$

Brockmole, J. R., Davoli, C., Abrams, R. A., \& Witt, J. K. (2013). The world within reach: Effects of hand posture and tool use on visual cognition. Current Directions in Psychological Science, 22(1), 38-44. doi: $10.1177 / 0963721412465065$

Bullier, J. (2001). Feedback connections and conscious vision. Trends in Cognitive Sciences, 5(9), 369-370. doi: 10.1016/S1364-6613\%2800\%2901730-7

Burke, L. (1952). On the tunnel effect. Quarterly Journal of Experimental Psychology, 4, 121-138. doi: 10.1080/17470215208416611 
Chakravarthi, R., \& Cavanagh, P. (2009). Recovery of a crowded object by masking the flankers: Determining the locus of feature integration. Journal of Vision, 9(10), 1-9. doi: 10.1167/9.10.4

Cousineau, D. (2005). Confidence intervals in within-subject designs: A simpler solution to Loftus and Masson's method. Tutorial in Quantitative Methods for Psychology, 1(1), 42-45.

de Monasterio, F. M. (1978). Properties of concentrically organized X and Y ganglion cells of macaque retina. Journal of Neurophysiology, 41(6), 1394-1417.

Derrington, A. M., \& Lennie, P. (1984). Spatial and temporal contrast sensitivities of neurones in the lateral geniculate nucleus of the macaque. Journal of Physiology, 357, 219-240.

Di Lollo, V. (2010). Iterative reentrant processing: A conceptual framework for perception and cognition (the blinding problem? No worries, mate). In V. Coltheart (Ed.), Tutorials in Visual Cognition. New York: Psychology Press.

Di Lollo, V., Enns, J. T., \& Rensink, R. A. (2000). Competition for consciousness among visual events: The psychophysics of reentrant visual processes. Journal of Experimental Psychology: General, 129(4), 481-507. doi: 10.1037/00963445.129 .4 .481

Dreher, B., Fukada, Y., \& Rodieck, R. W. (1976). Identification, classification and anatomical segregation of cells with X-like and Y-like properties in the lateral geniculate nucleus of old-world primates. The Journal of Physiology, 258(2), 433-452.

Duncan, J., Bundesen, C., Olson, A., Humphreys, G. K., Ward, R., Kyllingsbaek, S., . . Chavda, S. (2003). Attentional functions in dorsal and ventral 
simultanagnosia. Cognitive Neuropsychology, 20(8), 675-701. doi: $10.1080 / 02643290342000041$

Dux, P. E., Visser, T. A. W., Goodhew, S. C., \& Lipp, O. V. (2010). Delayed reentrant processing impairs visual awareness: An object substitution masking study. Psychological Science, 21(9), 1242-1247. doi:

$10.1177 / 0956797610379866$

Edwards, M. (2009). Common-fate motion processing: Interaction of the On and Off pathways. Vision Research, 49(4), 429-438. doi: 10.1016/j.visres.2008.11.010

Enns, J. T., \& Di Lollo, V. (2000). What's new in visual masking? Trends in Cognitive Sciences, 4(9), 345-352. doi: 10.1016/S1364$6613 \% 2800 \% 2901520-5$

Eriksen, C. W., \& Hoffman, J. E. (1972). Temporal and spatial characteristics of selective encoding from visual displays. Perception \& Psychophysics, 12(2B), 201-204. doi: 10.3758/BF03212870

Eriksen, C. W., \& St. James, J. D. (1986). Visual attention within and around the field of focal attention: A zoom lens model. Perception \& Psychophysics, 40(4), 225-240. doi: 10.3758/BF03211502

Eriksen, C. W., \& Yeh, Y.-Y. (1985). Allocation of attention in the visual field. Journal of Experimental Psychology: Human Perception and Performance, 11(5), 583-597. doi: 10.1037/0096-1523.11.5.583

Francis, G., \& Hermens, F. (2002). Comment on "Competition for consciousness among visual events: The psychophysics of reentrant visual processes" (Di Lollo, Enns, \& Rensink, 2000). Journal of Experimental Psychology: General, 131(4), 590-593. doi: 10.1037/0096-3445.131.4.590 
Gautheir, I., Tarr, M. J., Anderson, A. W., Skudlarski, P., \& Gore, J. C. (1999). Activation of the middle fusiform 'face area' increases with expertise in recognizing novel objects. Nature Neuroscience, 2(6), 568-573. doi: $10.1038 / 9224$

Gellatly, A., Pilling, M., Carter, W., \& Guest, D. (2010). How does target duration affect object substitution masking. Journal of Experimental Psychology: Human Perception and Performance, 36(5), 1267-1279. doi: 10.1037/a0018733

Goodale, M. A. (2008). Action without perception in human vision. Cognitive Neuropsychology, 25(7-8), 891-919. doi: 10.1080/02643290801961984

Goodale, M. A., \& Milner, A. D. (1992). Separate visual pathways for perception and action. Trends in Neurosciences, 15(1), 20-25. doi: 10.1016/0166$2236 \% 2892 \% 2990344-8$

Goodale, M. A., Milner, A. D., Jakobson, L. S., \& Carey, D. P. (1991). A neurological dissociation between perceiving objects and grasping them. Nature, 349(6305), 154-156. doi: 10.1038/349154a0

Goodale, M. A., \& Westwood, D. A. (2004). An evolving view of duplex vision: Separate but interacting cortical pathways for perception and action. Current Opinion in Neurobiology, 14(2), 203-211. doi: 10.1016/j.conb.2004.03.002

Goodhew, S. C., Gozli, D. G., Ferber, S., \& Pratt, J. (2013). Reduced temporal fusion in near-hand space. Psychological Science, 24(6), 891-900. doi: $10.1177 / 0956797612463402$

Goodhew, S. C., Pratt, J., Dux, P. E., \& Ferber, S. (2013). Substituting objects from consciousness: A review of object substitution masking. Psychonomic Bulletin \& Review, 20(5), 859-877. doi: 10.3758/s13423-013-0400-9 
Goodhew, S. C., Visser, T. A. W., Lipp, O. V., \& Dux, P. E. (2011). Competing for consciousness: Prolonged mask exposure reduces object substitution masking. Journal of Experimental Psychology: Human Perception and Performance, 37(2), 588-596. doi: 10.1037/a0018740

Gozli, D. G., West, G. L., \& Pratt, J. (2012). Hand position alters vision by biasing processing through different visual pathways. Cognition, 124(2), 244-250. doi: 10.1016/j.cognition.2012.04.008

Grill-Spector, K., Kourtzi, Z., \& Kanwisher, N. (2001). The lateral occipital complex and its role in object recognition. Vision Research, 41(10-11), 1409-1422. doi: 10.1016/S0042-6989(01)00073-6

Grill-Spector, K., Tammar, K., Hendler, T., \& Malach, R. (2000). The dynamics of object-selective activation correlate with recognition performance in humans. Nature Neuroscience, 3, 837-843.

Guest, D., Gellatly, A., \& Pilling, M. (2012). Reduced OSM for long duration targets: Individuation or items loaded into VSTM? Journal of Experimental Psychology: Human Perception and Performance, 38(6), 1541-1553. doi: $10.1037 / \mathrm{a} 0027031$

Haffenden, A. M., Schiff, K. C., \& Goodale, M. A. (2001). The dissociation between perception and action in the Ebbinghaus illusion: Nonillusory effects of pictorial cues on grasp. Current Biology, 11(3), 177-181. doi: 10.1016/S09609822(01)00023-9

Hein, E., \& Moore, C. M. (2012). Spatio-temporal priority revisited: The role of feature identity and similarity for object correspondence in apparent motion. Journal of Experimental Psychology: Human Perception and Performance, 38(4), 975-988. doi: 10.1037/a0028197 
Hesse, C., Ball, K., \& Schenk, T. (2012). Visuomotor performance based on peripheral vision is impaired in the visual form agnostic patient DF. Neuropsychologia, 50(1), 90-97. doi: 10.1016/j.neuropsychologia.2011.11.002

Hirose, N., Kihara, K., Mima, T., Ueki, Y., Fukuyama, H., \& Osaka, N. (2007). Recovery from object substitution masking induced by transient suppression of visual motion processing: A repetitive transcranial magnetic stimulation study. Journal of Experimental Psychology: Human Perception and Performance, 33(6), 1495-1503. doi: 10.1037/0096-1523.33.6.1495

Hollingworth, A., \& Franconeri, S. L. (2009). Object correspondence across brief occlusion is established on the basis of both spatiotemporal and surface feature cues. Cognition, 113(2), 150-166. doi: 10.1016/j.cognition.2009.08.004

Jakobson, L. S., Archibald, Y. M., Carey, D. P., \& Goodale, M. A. (1991). A kinematic analysis of reaching and grasping movements in a patient recovering from optic ataxia. Neuropsychologia, 29(8), 803-809. doi: $10.1016 / 0028-3932 \% 2891 \% 2990073-\mathrm{H}$

James, T. W., Culham, J., Humphreys, G. K., Milner, A. D., \& Goodale, M. A. (2003). Ventral occiptal lesions impair object recognition but not objectdirected grasping: An fMRI study. Brain: A Journal of Neurology, 126(11), 2463-2475. doi: 10.1093/brain/awg248

Kanwisher, N., \& Yovel, G. (2006). The fusiform face area: A cortical region specialized for the perception of faces. Philosophical Transactions of the Royal Society B, 361, 2109-2128.

Kveraga, K., Boshyan, J., \& Bar, M. (2007). Magnocellular projections as the trigger of top-down facilitation in recognition. Journal of Neuroscience, 27(48), 13232-13240. doi: 10.1523/jneurosci.3481-07.2007 
Lamme, V. A. F., \& Roelfsema, P. R. (2000). The distinct modes of vision offered by feedforward and recurrent processing. Trends in Neurosciences, 23(11), 571579. doi: 10.1016/S0166-2236(00)01657-X

Legge, G. E. (1978). Sustained and transient mechanisms in human vision: Temporal and spatial properties. Vision Research, 18(1), 69-81. doi: 10.1016/0042$6989 \% 2878 \% 2990079-2$

Leonova, A., Pokorny, J., \& Smith, V. C. (2003). Spatial frequency processing in inferred PC- and MC-pathways. Vision Research, 43, 2133-2139.

Lim, S. W. H., \& Chua, F. K. (2008). Object substitution masking: When does mask preview work? Journal of Experimental Psychology: Human Perception and Performance, 34(5), 1108-1115. doi: 10.1037/0096-1523.34.5.1108

Livingstone, M., \& Hubel, D. (1988). Segregation of form, color, movement, and depth: Anatomy, physiology, and perception. Science, 240(4853), 740-749. doi: 10.1126/science.3283936

Lleras, A., \& Moore, C. M. (2003). When the target becomes the mask: Using apparent motion to isolate the object-level component of object substitution masking. Journal of Experimental Psychology: Human Perception and Performance, 29(1), 106-120. doi: 10.1037/0096-1523.29.1.106

Luiga, I., \& Bachmann, T. (2008). Luminance processing in object substitution masking. Vision Research, 48(7), 937-945. doi: 10.1016/j.visres.2008.01.001

Luria, A. R. (1959). Disorders of "simultaneous perception" in a case of bilateral occipitoparietal brain injury. Brain, 82(3), 437-449. doi:

$10.1093 / \mathrm{brain} / 82.3 .437$ 
Maunsell, J. H., Nealey, T. A., \& DePriest, D. D. (1990). Magnocellular and parvocellular contributions to responses in the middle temporal visual area (MT) of the macaque monkey. Journal of Neuroscience, 10(10), 3323-3334.

McIntosh, R. D., \& Schenk, T. (2009). Two visual streams for perception and action: Current trends. Neuropsychologia, 47(6), 1391-1396. doi: 10.1016/j.neuropsychologia.2009.02.009

Merigan, W. H., \& Maunsell, J. H. (1993). How parallel are the primate visual pathways? Annual Review of Neuroscience, 16, 369-402. doi: 10.1146/annurev.ne.16.030193.002101

Mishkin, M., \& Ungerleider, L. G. (1982). Contribution of striate inputs to the visuospatial functions of parieto-preoccipital cortex in monkeys. Behavioural Brain Research, 6(1), 57-77. doi: 10.1016/0166-4328\%2882\%2990081-X

Mishkin, M., Ungerleider, L. G., \& Macko, K. A. (1983). Object vision and spatial vision: Two cortical pathways. Trends in Neurosciences, 6(10), 414-417. doi: $10.1016 / 0166-2236 \% 2883 \% 2990190-X$

Moore, C. M., \& Lleras, A. (2005). On the role of object representations in substitution masking. Journal of Experimental Psychology: Human Perception and Performance, 31(6), 1171-1180. doi: 10.1037/00961523.31.6.1171

Morey, R. D. (2008). Confidences intervals from normalized data: A correction to Cousineau (2005). Tutorial in Quantitative Methods for Psychology, 4(2), 6164.

Muller, M., Malinowski, P., Gruber, T., \& Hillyard, S. (2003). Sustained division of the attentional spotlight. [Letter]. Nature, 424(6946), 309-312. doi: $10.1038 /$ nature 01812 
Muller, N. G., Bartelt, O. A., Donner, T. H., Villringer, A., \& Brandt, S. A. (2003). A physiological correlate of the "zoom lens" of visual attention. Journal of Neuroscience, 23(9), 3561-3565.

Nassi, J. J., \& Callaway, E. M. (2007). Specialized circuits from primary visual cortex to V2 and area MT. Neuron, 55(5), 799-808. doi:

10.1016/j.neuron.2007.07.037

Neill, W. T., Hutchison, K. A., \& Graves, D. F. (2002). Masking by object substitution: Dissociation of masking and cueing effects. Journal of Experimental Psychology: Human Perception and Performance, 28(3), 682694. doi: 10.1037/0096-1523.28.3.682

Pammer, K., \& Lovegrove, W. (2001). The influence of color on transient system activity: Implications for dyslexia research. Perception \& Psychophysics, 63(3), 490-500.

Pelli, D. G., \& Tillman, K. A. (2008). The uncrowded window of object recognition. Nature Neuroscience, 11(10), 1129-1135. doi: 10.1038/nn.2187

Pilling, M., \& Gellatly, A. (2010). Object substitution masking and the object updating hypothesis. Psychonomic Bulletin \& Review, 17(5), 737-742. doi: 10.3758/PBR.17.5.737

Pokorny, J. (2011). Review: Steady and pulsed pedestals, the how and why of postreceptoral pathway separation. Journal of Vision, 11(5), 1-23. doi: $10.1167 / 11.5 .7$

Posner, M. I., \& Cohen, Y. (1984). Components of visual orienting. In H. Bouma \& D. Bouwhuis (Eds.), Attention \& Performance X. Hillsdale: Erlbaum. 
Previc, F. H. (1990). Functional specialization in the lower and upper visual fields in humans: Its ecological origins and neurophsyiological implications. Behavioral and Brain Sciences, 13(3). doi: 10.1017/S0140525X00080018

Pylyshyn, Z. W., \& Storm, R. W. (1988). Tracking multiple independent targets: Evidence for a parallel tracking mechanism. Spatial Vision, 3, 179-197.

Ramachandran, V. S., \& Cobb, S. (1995). Visual attention modulates meta-contrast masking. Nature, 373(6509), 66-68.

Richard, A. M., Luck, S. J., \& Hollingworth, A. (2008). Establishing object correspondence across eye movements: Flexible use of spatiotemporal and surface information. Cognition, 109(1), 66-88. doi:

10.1016/j.cognition.2008.07.004

Schiller, P. H., \& Logothetis, N. K. (1990). The color-opponent and broad-band channels of the primate visual system. Trends in Neurosciences, 13(10), 392398. doi: 10.1016/0166-2236(90)90117-s

Shelley-Tremblay, J., \& Mack, A. (1999). Metacontrast masking and attention. Psychological Science, 10(6), 508-515. doi: 10.1111/1467-9280.00197

Tapia, E., \& Breitmeyer, B. G. (2011). Visual consciousness revisited: Magnocellular contributions to conscious and nonconscious vision. Psychological Science, 22(7), 934-942. doi: 10.1177/0956797611413471

Wenderoth, P. (1996). The effects of the contrast polarity of dot-pair partners on the detection of bilateral symmetry. Perception, 25(7), 757-771. doi: $10.1068 / \mathrm{p} 250757$

Werner, H. (1935). Studies on counter: I. Qualitative analyses. American Journal of Psychology, 47, 40-64. doi: 10.2307/1416707 
Wiesel, T. N., \& Hubel, D. H. (1966). Spatial and chromatic interactions in lateral geniculate body of rhesus monkey. Journal of Neurophysiology, 29(6), 11151156.

Yeshurun, Y., \& Sabo, G. (2012). Differential effects of transient attention on inferred parvocellular and magnocellular processing. Vision Research, 74, 21-29. doi: 10.1016/j.visres.2012.06.006

Zihl, J., Von Cramon, D., \& Mai, N. (1983). Selective disturbance of movement vision after bilateral brain damagae. Brain, 106(2), 313-340. doi: 10.1093/brain/106.2.313 
Figure 1

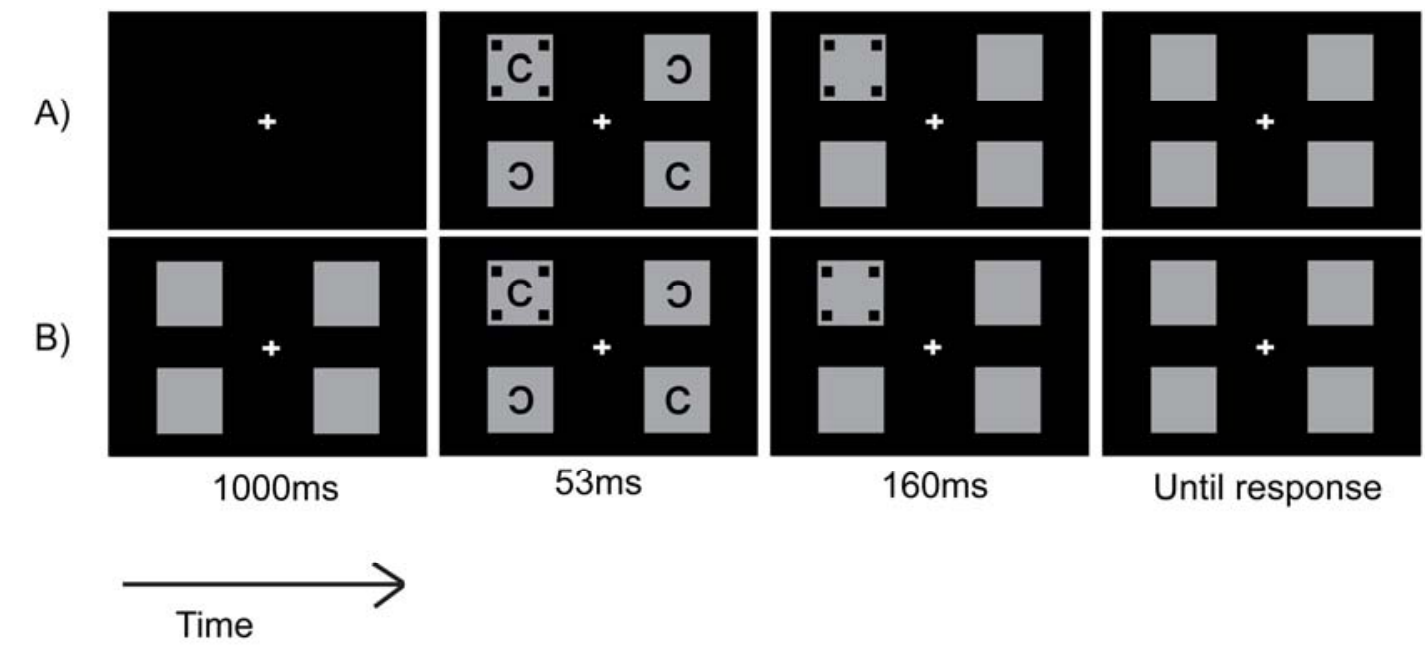

Figure 1. A schematic illustrations of A) a pulsed-pedestal and B) a steadypedestal trial in Experiment 1. Participants' task was to identify the location of the gap in the target Landolt $\mathrm{C}$ (left vs right). Both rows represent delayedmask offset trials. For simultaneous mask offset trials ( $0 \mathrm{~ms}$ trailing mask), panel 3 would consist of blank pedestals for $160 \mathrm{~ms}$. 
Figure 2

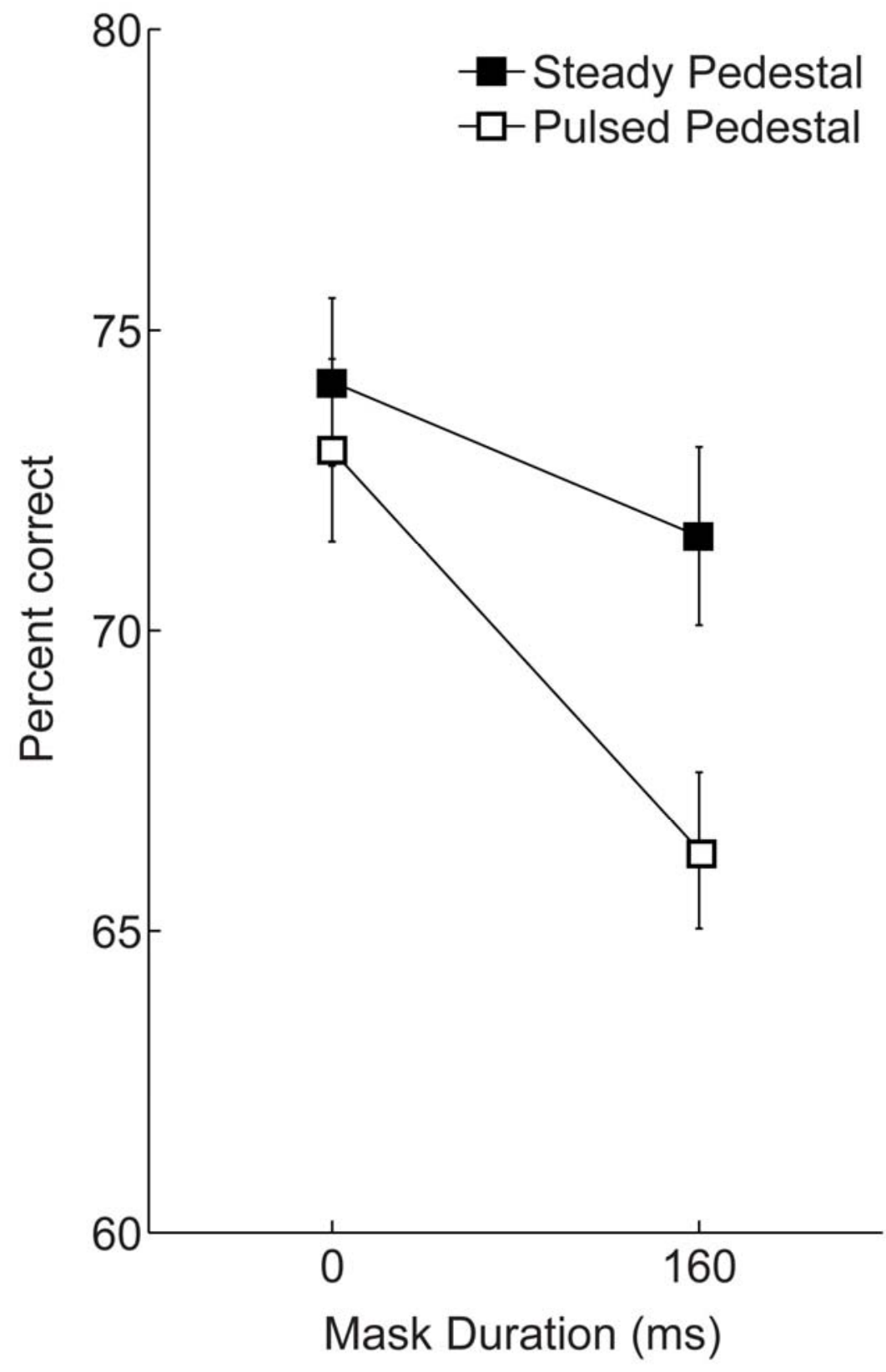

Figure 2. Percent correct for steady and pulsed pedestal conditions as a function of trailing mask duration $(0 \mathrm{~ms}=$ simultaneous target and mask offset, $160 \mathrm{~ms}=$ delayed mask offset) in Experiment 1. Error bars are within-subjects error bars, using the correction originally described by Cousineau (2005) and updated by Morey (2008). 


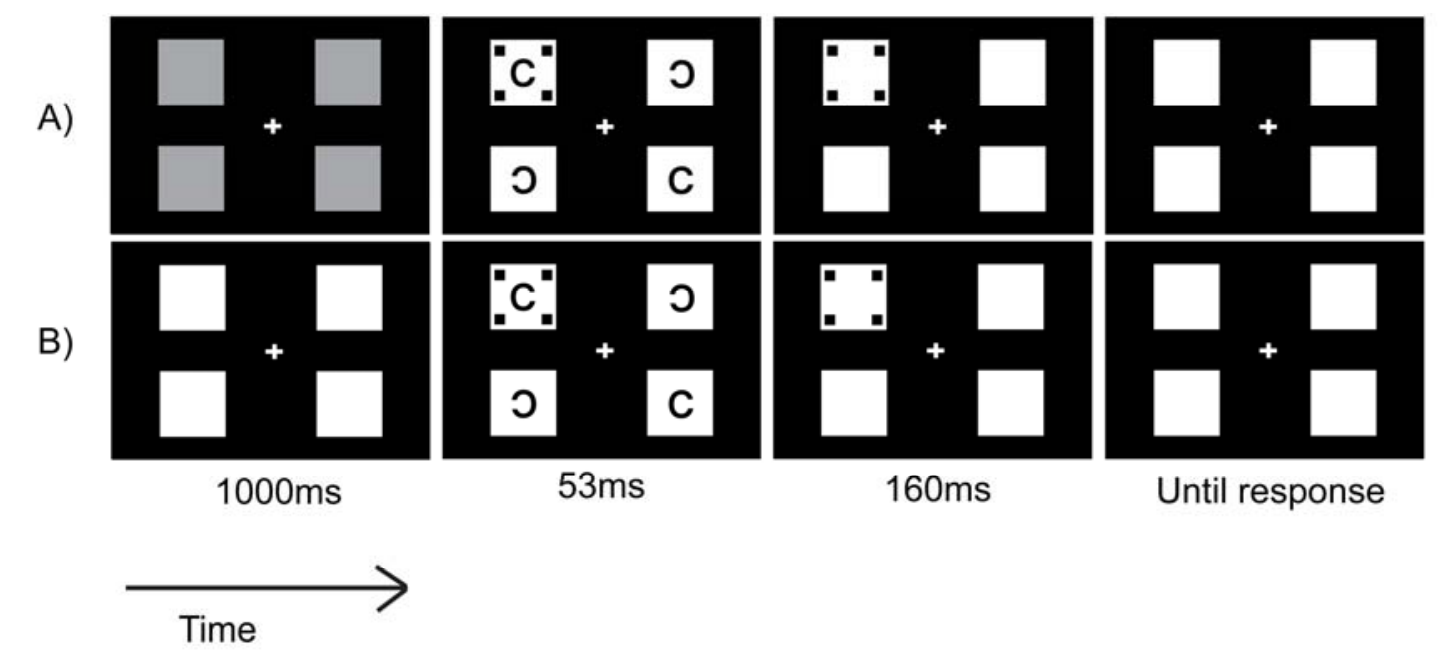

Figure 3. A schematic illustrations of A) a pulsed-pedestal and B) a steadypedestal trial in Experiment 2. Participants' task was to identify the location of the gap in the target Landolt $\mathrm{C}$ (left vs right). Both rows represent delayedmask offset trials. For simultaneous mask offset trials ( $0 \mathrm{~ms}$ trailing mask), panel 3 would consist of blank pedestals for $160 \mathrm{~ms}$. 
Figure 4

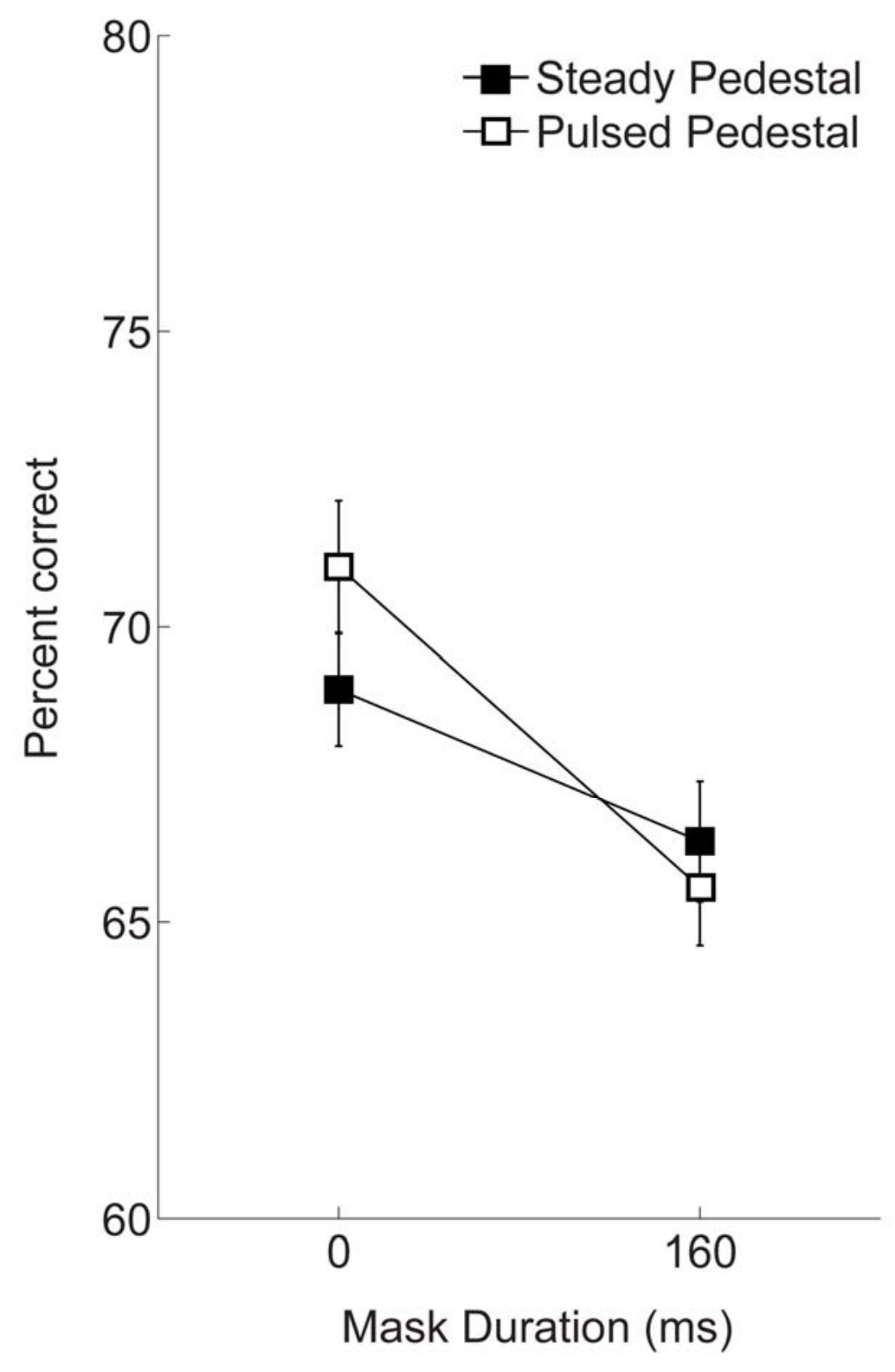

Figure 4. Percent correct for steady and pulsed pedestal conditions as a function of trailing mask duration $(0 \mathrm{~ms}=$ simultaneous target and mask offset, $160 \mathrm{~ms}=$ delayed mask offset) in Experiment 2. Error bars are within-subjects error bars, using the correction originally described by Cousineau (2005) and updated by Morey (2008). 